\title{
To The Covid-19 Pandemic Experience: A View from Russia
}

\section{A la experiencia de la pandemia de Covid-19: una vista desde Rusia}

\author{
Maksim Maksimov \\ Plekhanov Russian University of Economics, Russia, 117997, Stremyanny Lane, 36, Moscow, \\ Russian Federation.
}

ORCID: 0000-0001-9247-1819

Natalia Prodanova

Plekhanov Russian University of Economics, Russia, 117997, Stremyanny Lane, 36, Moscow, Russian Federation.

ORCID: 0000-0001-5140-2702:

Anatoliy Kolesnikov

Plekhanov Russian University of Economics, Russia, 117997, Stremyanny Lane, 36, Moscow,

Russian Federation

ORCID: 0000-0003-1776-2207

Aleksandr Melnikov

Plekhanov Russian University of Economics, Russia, 117997, Stremyanny Lane, 36, Moscow,

Russian Federation

ORCID: 0000-0002-9878-4282

\section{Ona Grazyna Rakauskiene}

Plekhanov Russian University of Economics, Russia, 117997, Stremyanny Lane, 36, Moscow, Russian Federation, Mykolas Romeris University, Ateities st. 20, LT-08303 Vilnius, Lithuania ORCID: 0000-0003-0007-0570

Egor Denisovich Ignashov

National University of Oil and Gas «Gubkin University»119991 Moscow, Russian Federation ORCID:0000-0002-4391-5855

Inessa Makedonovna Kalyakina

Don state technical University, Russia

ORCID:0000-0002-2688-1454

* Correspondence

Email: max_maximoff@mail.ru
Citation:

Maksim Maksimov, Natalia Prodanova, Anatoliy Kolesnikov, Aleksandr Melnikov, Ona Grazyna Rakauskiene, Egor Denisovich Ignashov, Inessa Makedonovna Kalyakina. (2021). To The Covid-19 Pandemic Experience: A View from Russia. Propósitos $y$ Representaciones, 9 (SPE3), e1134. Doi: http://dx.doi.org/10.20511/pyr2021.v9nSPE3.1134 


\begin{abstract}
In the presented work, an attempt to assess the correlation between the performance indicators of several sectors of the Russian economy and a set of restrictive measures taken by the Government of our country against the backdrop of the fight against the COVID-19 pandemic is made. In addition, a comparative analysis of the impact of this pandemic on the neighboring countries of Russia, which, in the recent past, were part of the USSR and, therefore, have similar health care organization structures, is carried out.
\end{abstract}

Keywords: contingency plan administration, crisis response, economy of crisis, COVID-19, anticrisis management, national economy.

\title{
Resumen
}

En el trabajo presentado, se intenta evaluar la correlación entre los indicadores de desempeño de varios sectores de la economía rusa y un conjunto de medidas restrictivas tomadas por el Gobierno de nuestro país en el contexto de la lucha contra la pandemia de COVID-19. hecho. Además, se realiza un análisis comparativo del impacto de esta pandemia en los países vecinos de Rusia, que en el pasado reciente formaban parte de la URSS y, por tanto, cuentan con estructuras organizativas sanitarias similares.

Palabras clave: administración de planes de contingencia, respuesta a crisis, economía de crisis, COVID-19, gestión anticrisis, economía nacional.

\section{Introduction}

The global blow that the COVID-19 pandemic has inflicted on the global economy has to be assessed and comprehended. But it is already obvious that the forced introduction of restrictive measures of varying degrees of strictness (travel bans, social distancing, quarantine, and others) lead to a drop in demand, the closure of entire sectors of the national economy (e.g., the fitness and beauty industry, travel and tourism, etc.), increased unemployment, trigger off supply chain disruptions and other negative consequences (Tarasova et al., 2020; Filin et al., 2020; Genkin et al., 2020). The above mentioned especially strongly affects small and medium-sized businesses, which do not have deep financial and resource reserves, and often have to carry out their operating activities at the expense of borrowed funds. In the developed countries of Europe (primarily in Germany, Austria and France), such enterprises receive quite serious attention from the state. This is reflected in concessional lending, a moratorium on tax deductions, direct benefits for the payment of wages to employees. Alas, in the context of Russian economic reality, such programs seem unlikely. Against the background of a decrease in available funds, many enterprises are shut down activities related to the innovation agenda, business acceleration, abandoning the modernization of production processes, switching to a mode of saving money on labor costs and personnel development (Maksimov et al., 2020; Velikorossov et al., 2020).

At the same time, in contrast to the countries mentioned above, crises in the recent history of Russia (since 2000) have a certain cyclicality and structure. It is becoming obvious that the current situation in the Russian economy requires an analysis of the nature of crises and drawing lessons from the past, since a rich experience has been accumulated in overcoming crises in our country.

\section{Methodology}

In the framework of the presented work, the authors used the following research methods:

- at the theoretical level: study and generalization, formalization, analysis and synthesis, induction and deduction, axiomatics;

- $\quad$ at the experimental-theoretical level: experiment, analysis, modeling, synthesis;

- at an empirical level: observation, measurement, comparison. 


\section{Analysis}

At the end of 2019, an "trade-off" on the exchange began between the prices of gold (reserve asset, growth) and copper (investment commodity, decline). In January, the Bloomberg Commodities index showed that prices for copper over the past month fell by $12.6 \%$, nickel fell by $9 \%$, tin - by $7 \%$, aluminum - by $6 \%$. Meanwhile, it is the metal price index that has always shown a strong correlation with the growth indicators of the world economy. Its growth is evidenced by the revival in this market and the rise in metal prices, and the slowdown in growth is indicated by the sluggish situation on the metals market, a decrease in the price index for them. Especially copper, unlike gold, is not an investment commodity, but is widely used in production. And the fall in demand is characterized by a decline in production, investors are shifting to protective instruments, in this case, gold, the price has risen.

Its growth is evidenced by the revival in this market and the rise in metal prices, and the slowdown in growth is indicated by the sluggish situation on the metals market, a decrease in the price index for them. Especially copper, unlike gold, is not an investment commodity, but is widely used in production. And the fall in demand is characterized by a decline in production, investors are shifting to protective instruments, in this case, gold, the price has risen.

Particularly impressive was the collapse of Japan's GDP in the fourth quarter of 2019, which fell $6.3 \%$ year-on-year.

There were also signals of the crisis in the Russian economy. Thus, in November, for the seventh month in a row, business activity in industry continued to fall.

IHS Markit and Alfa-Bank conducted a survey of almost 4 thousand individual entrepreneurs, managers and owners of companies with revenues of up to 350 million rubles per year, and found that the level of pessimism of entrepreneurs regarding the current and future situation is in the region of 2015, which is considered the peak crisis.

In December, the head of the Accounts Chamber, A. Kudrin, reported to V. Putin on the non-fulfillment of budget expenditures in 2019 by 1 trillion rubles, which has never happened before, linking this phenomenon with the bureaucratization of administrative procedures, which the government itself is not able to overcome. As a result, both economic growth, and consumer, and investment demand are noticeably underfunded.

According to Russian Railways, at the end of the year, the loading on the railroad in December decreased by $2 \%$ in annual terms. By the end of the whole year, loading decreased by $0.9 \%$.

According to the Association of European Businesses, in November car sales in Russia decreased by $6.4 \%$ year-to-year. The decline started in late summer and accelerated in October.

In the frame of our study, it will be appropriate to consider the cause-and-effect relationships between the actions of state and international structures and the reactions of the Russian market. To measure this correlation, the most indicative will be the dynamics of the MICEX index, the most significant trading platform in Russia.

On December 31, 2019, Chinese authorities reported an outbreak of pneumonia of unknown origin in Wuhan City, Hubei Province. 27 people were hospitalized, 7 in critical condition. This event had virtually no effect on the MICEX index. Currently, oil prices reach their maximum of $\$$ 69.59 per barrel. The market still did not react in any way to such, as we understand now, the most important events. However, starting in the second decade of January, as the pandemic gained rates in Western Europe and the United States, the main economic indices of these countries began to decline significantly. Oil prices also went down sharply. And if the Russian stock market reacted to the first fact rather indifferently, then the drop-in oil rates created a sharp downward trend. Figure 1 represents the main facts and actions executed by Russian Government since the first warnings of the COVID-19 pandemic. 
As we can see on the graph the situation was stabilized by the statement made by the Prime Minister of the Russian Federation M.V. Mishustin on July 15 about the peak of the pandemic. However, on the $13^{\text {th }}$ of August the increase in cases of more than 14 thousand per day caused a decrease in stock prices.

It is important that messages related to the actions of the state to isolate the country from external infection play a positive role, at the same time, as soon as the authorities decide to restrict the citizens' latitude, the market reacts negatively. The chart shows that after the negative information the stock market falls, but then recovers rather quickly and only the next event associated with the restrictive actions of the authorities lead to its fall.

At the same time, the economy does not have such a catastrophic reaction to the next sanctions against Russia, endless political games around our infrastructure and oil and gas projects.

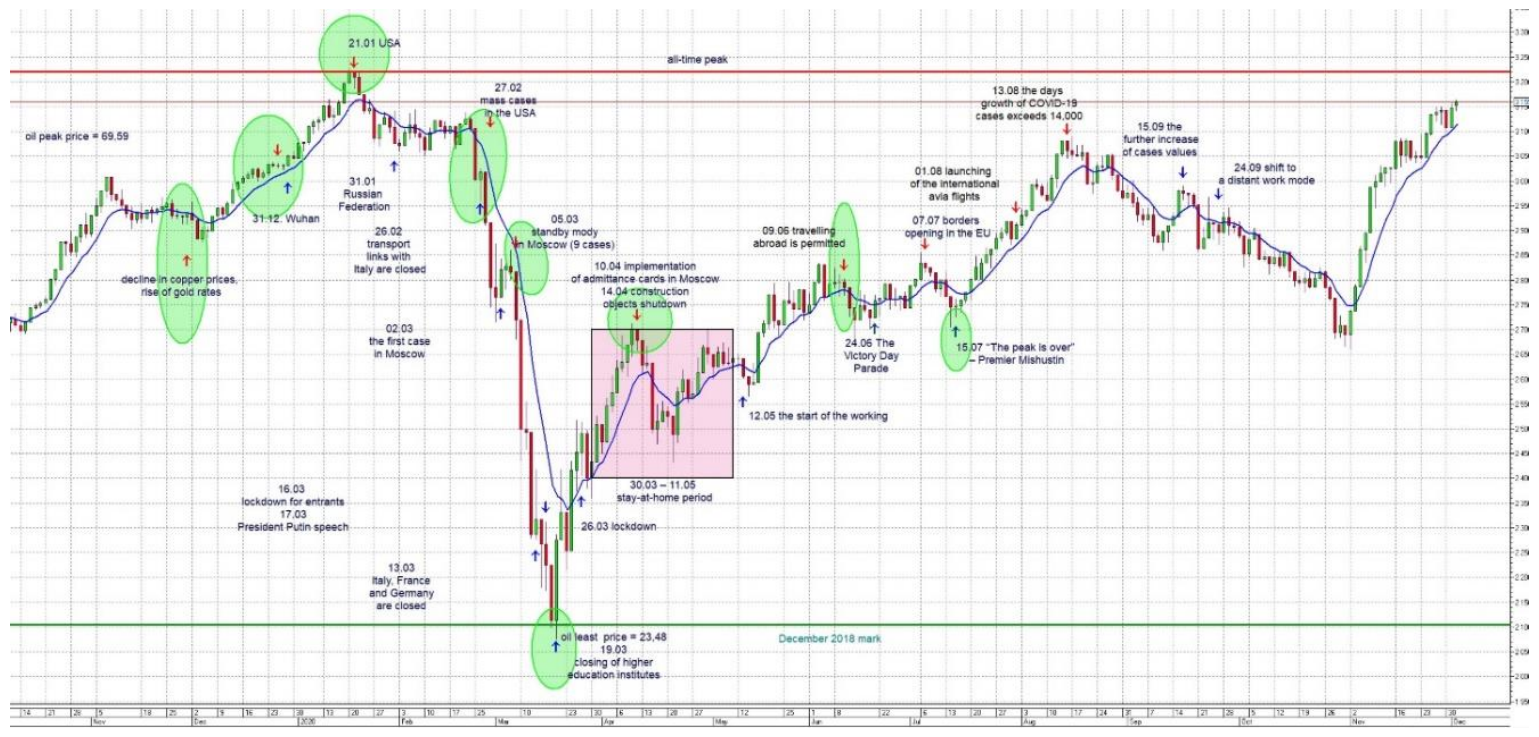

Figure 1. Dynamics of the MICEX index.

For the Russian Federation, one of the most negative factors was the sharp drop in world oil prices due to a significant decrease in global consumption and especially after the breakdown of the Russian-OPEC deal. The OPEC + deal was largely doomed long before the events in Vienna on March 6, the interests of the parties involved are largely polarized, the story of the coronavirus epidemic only accelerated this process.

A significant negative factor for the Russian economy turned out to be the long holidays in May and the bans on the work of many companies, announced first by the federal authorities and then by the authorities of most regions.

Small and medium-sized businesses are especially affected in this situation, as well as a sharp decline in household incomes, and accordingly, consumption and aggregate demand for products and services decrease.

The calculations made by the scientists of the Institute of National Economic Forecasting show that the spheres of activity that directly serve the population, in which, as a rule, small enterprises are involved, have suffered to a greater extent (Figure 2, Figure 3). 


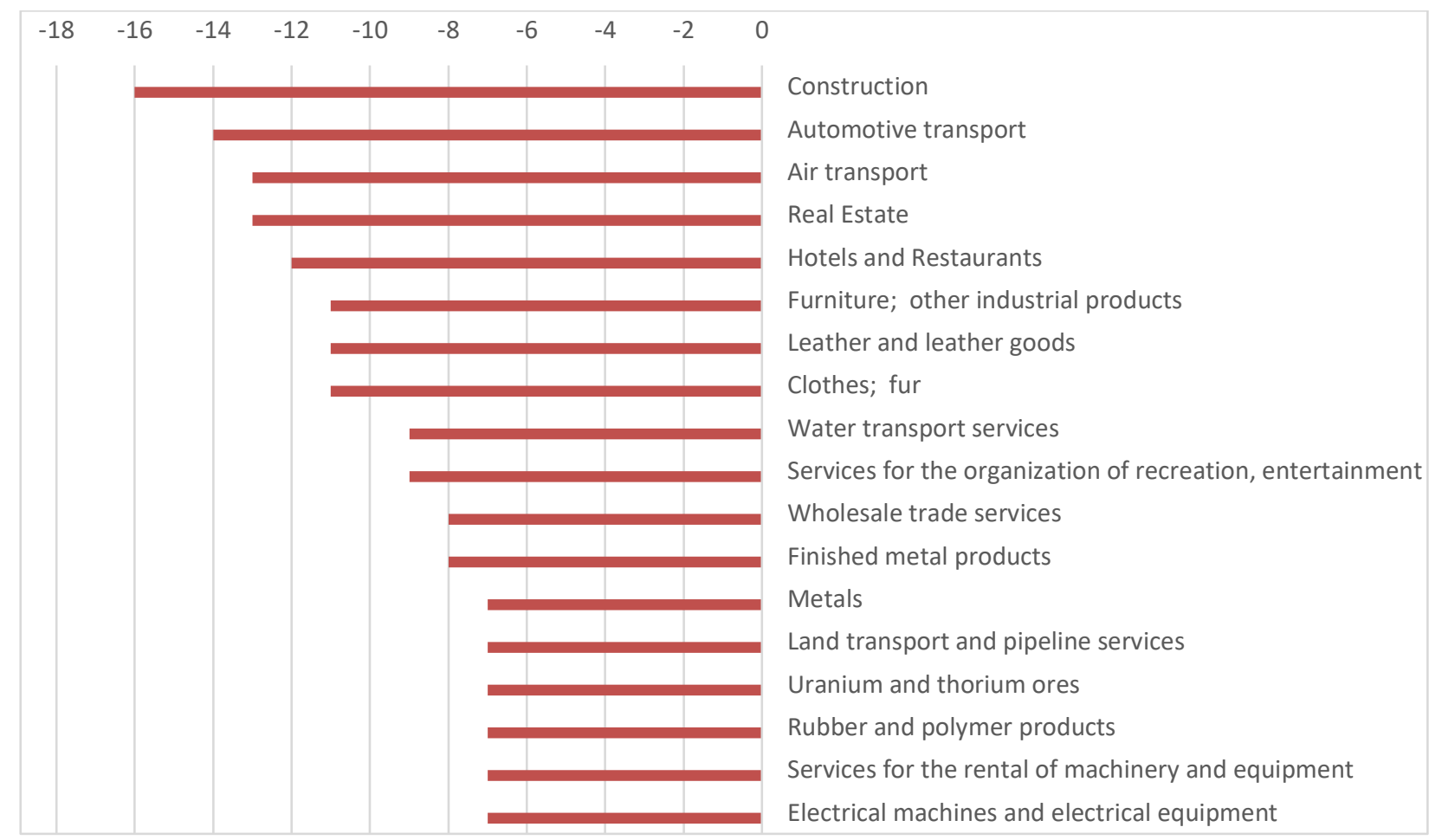

Figure 2. Activities with a production decline of more than $6 \%$.

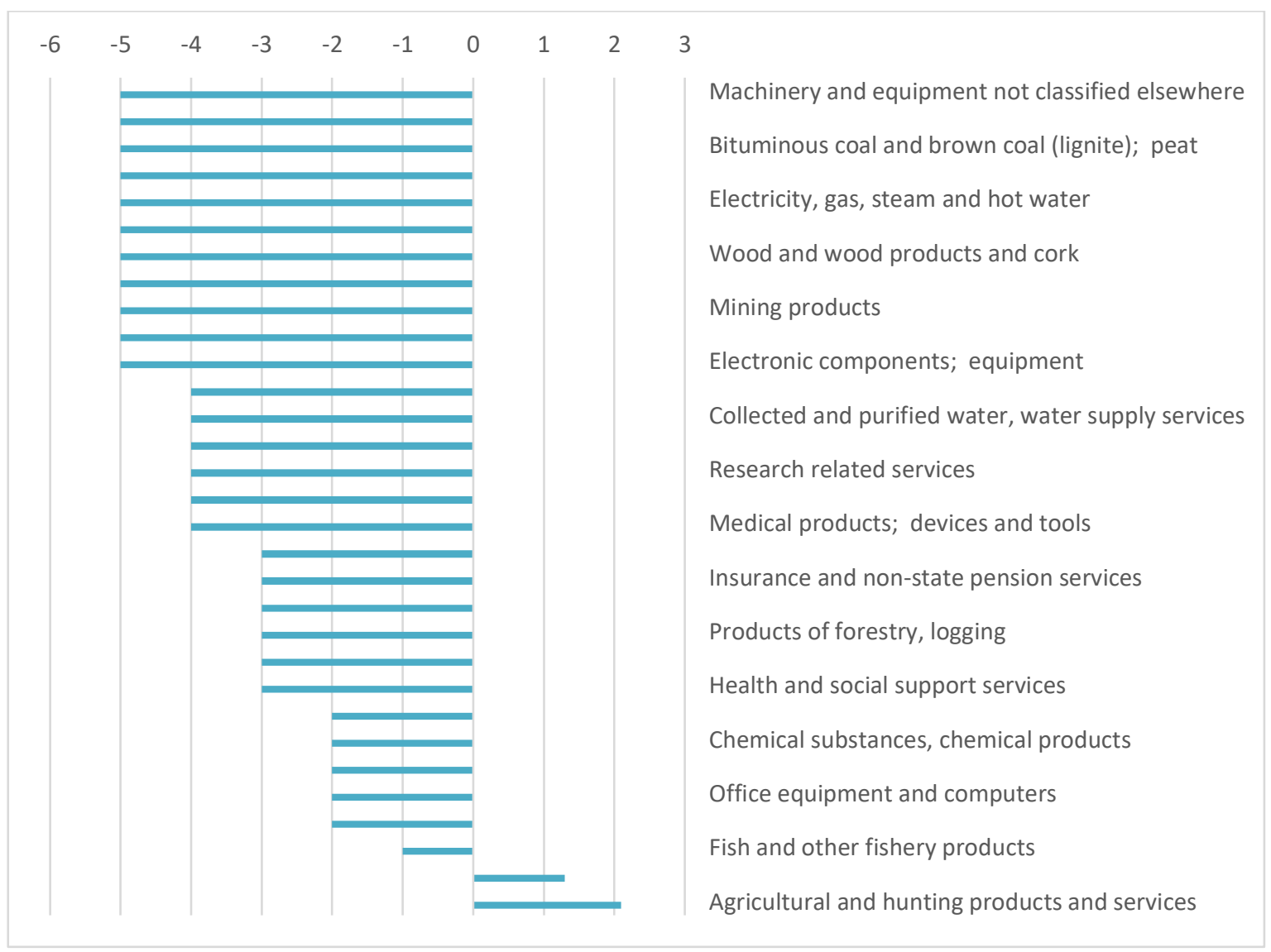

Figure 3. Activities with a production decline of less than $6 \%$.

In this situation, the Russian government faces a difficult choice. On the one hand, it is required to compensate for the shock effects on the backbone industries: oil and gas production and processing, power generation, metallurgy, construction, transport.

At the same time, measures in the field of supporting the population and small and mediumsized businesses give a large multiplier effect, not because small business plays a significant role in 
the economy (according to recent estimates, its share does not exceed 12\% of GDP), but due to the fact that today a significant proportion of workers are involved in these structures (approximately 18 million people or more than $25 \%$ of the country's working-age population).

\section{Main conclusions}

1. Analyzing the dynamics, in the context of the actions of the authorities, we can conclude that the downturn in the economy was caused not by the global problems that exist in it, but by the actions of regulatory authorities.

2. The notorious optimization of healthcare, which began during the presidency of D.A. Medvedev, has costed Russia highly during the pandemic. Huge funds were spent on the emergency deployment of hospital facilities; to combat the coronavirus, mobile teams, consisting of specialist doctors who were removed from specialized work were urgently formed. This arrangement led to a disaster with the planned provision of the population with medical services. But ten years ago, the expert community (including the authors of the article) warned the authorities about the inadmissibility of implementing programs to optimize (that is, in fact, to reduce funding) medicine.

3. Regularity of the crisis. As a rule, the current crisis has much in common with the previous ones, and the methods of dealing with their negative consequences are chosen approximately the same. A distinctive feature of the current situation is that if earlier the main goals were to restore the economy, save businesses, fight for the restoration of the payment system, etc., now we are talking about saving people's lives.

\section{References}

Filin, S.A., Velikorossov, V.V., Akulinin, F.V., Kolesnikov, A.V. (2020). SMALL BUSINESS: RECESSION TURNING INTO STAGNATION AND PANDEMIC-TRENDS AND CHALLENGES. Conf. Innovations in the management of socio-economic systems (RCIMSS-2020). Moscow, 268-275.

Genkin, E., Filin, S., Velikorossov, V., Kydyrova, Z., \& Anufriyev, K. (2020). The fourth industrial revolution: personnel, business and state. E3S Web of Conferences. 1st International Conference on Business Technology for a Sustainable Environmental System, BTSES, 04012. https://doi.org/10.1051/e3sconf/202015904012

Maksimov, M.I., Akulinin, F.V., Velikorossov, V.V., Prodanova, N.A., Zaharov, A.K., Zhanguttina, G.O. (2020). Acceleration of Business: A Comparative Analysis of Companies Development Methods. Journal of Advanced Research in Dynamical and Control Systems, 12(6), 2248-2253.

Tarasova, A., Velikorossov, V., Filin, S., Ibraimova, S., \& Yakushev, A. (2020). Development of a set of limits for the main performance indicators of energy-generating companies. In E3S Web of Conferences (Vol. 159, p. 07001). EDP Sciences.

Velikorossov, V.V., Maksimov, M.I., Lebedev, V.V., Khudaibergenov, A.K., Khachaturyan, M.V., Pavlova, V.V. (2020). Automation of Quality Control Process without the Usage of Complex Information Systems. 2nd International Conference on Pedagogy, Communication and Sociology (ICPCS 2020),185-188.- DOI 10.12783/dtssehs/icpcs2020/33865 